\title{
In het kort
}

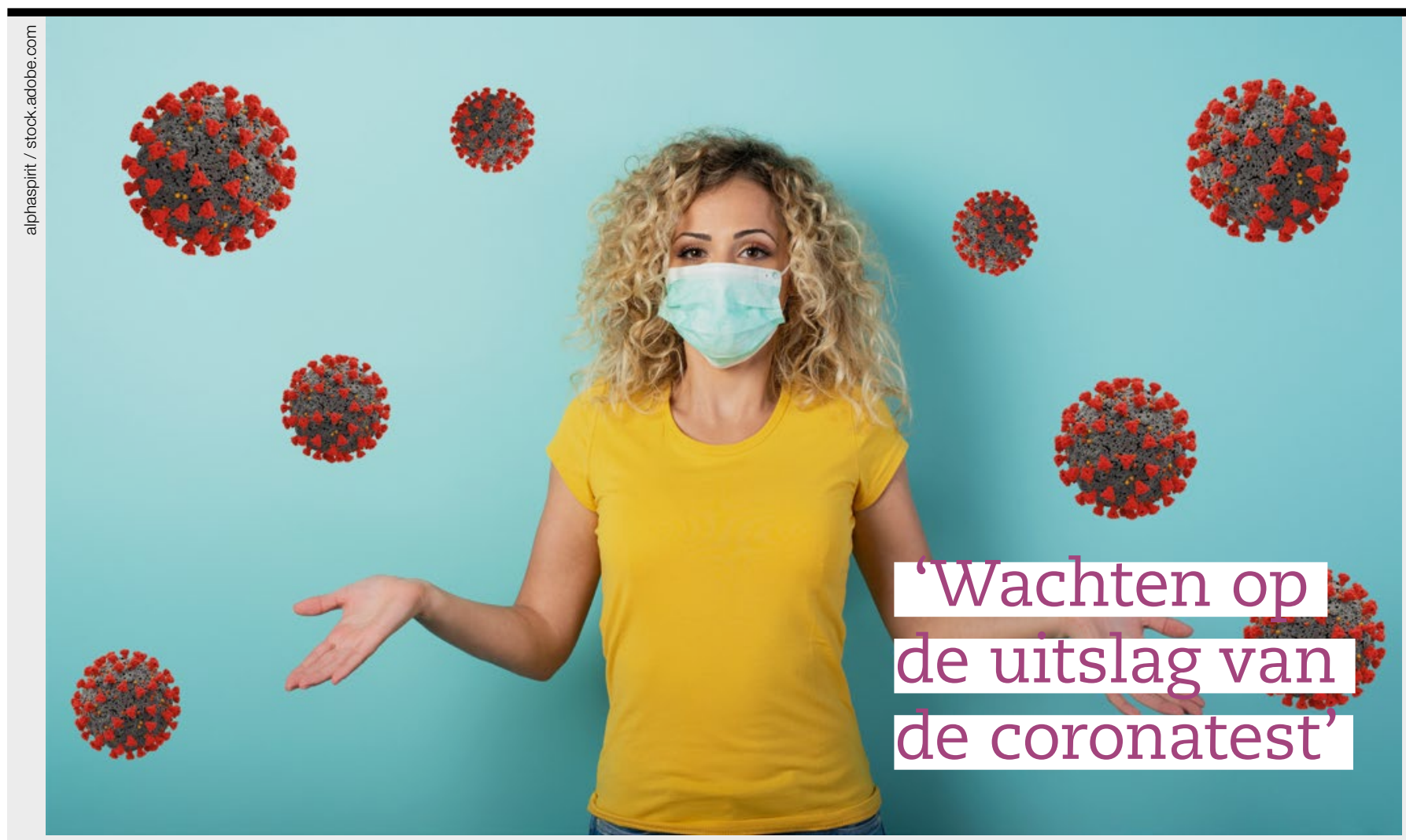

\section{Nog steeds groot personeelstekort}

Meer dan de helft van de kinderopvangorganisaties heeft een tekort aan inzetbaar personeel. Door onderbezetting neemt de druk op medewerkers toe, sommigen zeggen (bijna) om te vallen. Dat blijkt uit een peiling van Kinderopvang werkt! (oktober 2020). Ook voor de coronacrisis kampte de kinderopvangsector al met grote personeelstekorten, maar tijdens de huidige crisis lopen deze tekorten -vanzelfsprekend - verder op. In de dagopvang ervaart 45 procent van de organisaties een tekort aan pedagogisch medewerkers, in de buitenschoolse opvang is dat zelfs 52 procent.

Arbeidsmarktplatform Kinderopvang Werkt! brengt door middel van een quickscan de arbeidsmarktontwikkelingen in kaart. In de periode van 8 tot en met 22 oktober zijn door middel van een digitale enquête gegevens verzameld. Er is gebruik gemaakt van een panel, dat is opgebouwd uit de eerdere meting. Hierin zaten 180 or- ganisaties. Van deze groep hebben 89 deelgenomen aan de tweede enquête. Parallel hieraan zijn via social media nog eens 33 kinderopvangorganisaties bereid gevonden om deel te nemen aan de enquête. De in totaal 122 organisaties vertegenwoordigen in totaal ruim 27.000 medewerkers.

87 procent van de organisaties heeft te maken met niet-inzetbare medewerkers als gevolg van de coronamaatregelen. Dit percentage is verdubbeld in vergelijk met de meting van juni 2020. Toen ging het nog om 44 procent van de organisaties. De voornaamste reden dat medewerkers niet inzetbaar zijn is afname of wachten op de uitslag van de coronatest (93 procent). Een deel van de organisaties geeft ook aan medewerkers niet te kunnen inzetten omdat zij behoren tot de risicogroep (18 procent), of dat een partner/huisgenoot hiertoe behoort (17 procent). Gemiddeld heeft 51 procent van de kinderopvangorganisaties moeilijk vervulbare vaca- tures. Vooral grote organisaties kampen daarmee (78 procent). Bij middelgrote organisaties heeft 45 procent moeite om vacatures te vervullen, en bij kleine organisaties 27 procent. Om personeelstekorten en uitval op te vangen, werken medewerkers vaak meer dan normaal. In verschillende organisaties vallen medewerkers daardoor (bijna) om. Ze zijn moe, worden eerder ziek en dit leidt weer tot verzuim. Een deel van de respondenten verwacht dat door onderbezetting groepen bij hun organisatie of elders zullen moeten sluiten.

10 procent van de organisaties verwacht de komende drie maanden meer leerwerkplekken te hebben voor bbl-studenten dan voor de coronacrisis. 8 procent verwacht minder plekken te hebben en 11 procent verwacht geen plekken te hebben. 66 procent van de organisaties verwacht geen veranderingen in de hoeveelheid bol-stageplaatsen die ze de komende drie maanden aanbieden. 


\section{Eigen post-hbo opleiding SWK}

De SWKGroep, een grote organisatie voor onder meer kinderopvang in Zuid-Holland, ontwikkelde een eigen post-hbo opleiding voor het middenmanagement. Onlangs kregen de eerste 14 medewerkers hun diploma. Ze volgden de opleiding in hun eigen tijd. In februari start een volgende groep. De opleiding duurt een jaar en omvat 39 lesavonden plus thuisstudie. De deelnemers leren onder andere over persoonlijk leiderschap, het klantperspectief komt aan bod en is er aandacht voor teamvaardigheden. 'De behoefte aan een interne post-hbo opleiding was groot,' zegt Nadine Bongers, hoofd opleidingscentrum van de SWKGroep. 'We willen actief in kunnen spelen op wat de huidige tijdgeest vraagt. Daarom zijn we op zoek gegaan naar een passende, aanvullende managementopleiding.'

\section{Voor het eerst minder kinderen naar de opvang}

Het gemiddeld aantal kinderen dat gebruik maakt van de kinderopvang nam in het tweede kwartaal van 2020 met 3.000 af ten opzichte van het eerste kwartaal. Voor het eerst in jaren is er geen sprake van toename, blijkt uit de tweede kwartaalrapportage kinderopvang. In deze rapportage zijn de gevolgen van de coronacrisis voor het eerst zichtbaar. En dat is meteen te zien aan het aantal kinderen dat gebruik maakte van kinderopvangtoeslag: gemid-

\section{'Lichte stijging bso'}

deld waren dat er 844.000 in het tweede kwartaal van 2020, 3.000 minder dan in het eerste kwartaal. Enkel de buitenschoolse opvang kende in het tweede kwartaal een lichte stijging van 1.000 kinderen, naar 410.000 in totaal. De dagopvang zag een daling van gemiddeld 353.000 kinderen naar 349.000 kinderen. Ook de gastouderopvang zag het aantal kinderen gemiddeld met 1.000 afnemen.

\section{Groot deel kampt niet met overmacht}

71 procent van de kinderopvangorganisaties heeft in coronatijd (nog) niet te maken gehad met overmacht, en daarmee de kans op boetes tijdens inspecties. Zo'n 40 procent heeft lokale afspraken kunnen maken met de gemeente, de toezichthouder of veiligheidsregio over het toezicht in de kinderopvang. Dit blijkt uit een enquête door brancheorganisaties BMK en BK. Die peilden in de week van 7 tot en met 13 oktober onder hun leden hoe het is gesteld met het toezicht en de handhaving op de regels en wat de inzet en de kosten zijn om medewerkers aan de slag en locaties open te houden. In totaal hebben ruim 110 kinderopvangorganisaties de enquête ingevuld.

In de situaties waarin wel sprake is geweest van overmacht (24 procent van de respondenten) wordt de situatie zowel beschreven als een overtreding geconstateerd. In bijna 10 procent van de gevallen van een constate- ring werd er door de gemeente gehandhaafd. Door de regels en voorschriften omtrent COVID-19 is een deel van de medewerkers niet inzetbaar. Het gaat hierbij om medewerkers die wachten op een uitslag van een test, zelf (of een huisgenoot) behoren tot een risicogroep of zijn meer dan 28 weken zwanger. Gemiddeld geldt dat voor zo'n 8 procent van het personeel. In de week voorafgaand aan de enquête (30 september tot en met 7 oktober) heeft gemiddeld 11 procent van de respondenten een groep of locatie moeten sluiten.

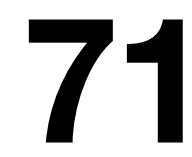

procent van organisaties heeft (nog) niet te maken met overmacht 


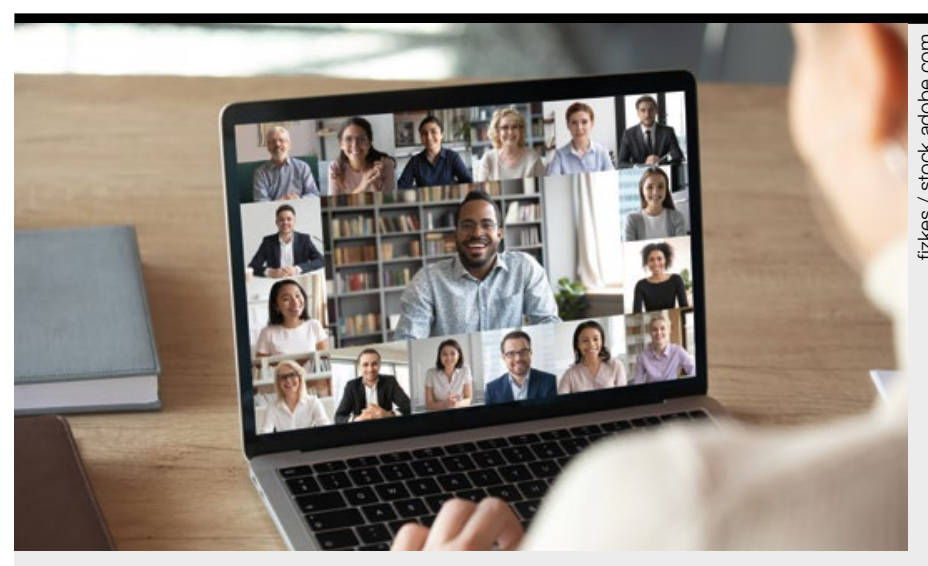

\section{Overname Netwerk}

Het Netwerk Professionals Kinderopvang biedt vakgenoten de gelegenheid om op een informele manier inzichten en ervaringen uit te wisselen over onderwerpen passend bij een van de kringen (Controllers, Facilitair, Inkoop en Marketing). Vanaf januari 2021 valt het Netwerk Professionals Kinderopvang onder de vlag van het Waarborgfonds \& Kenniscentrum Kinderopvang. Oprichter Tony Weggemans blijft als expert bij de kringen en het Waarborgfonds betrokken.

Een groep ondernemers van kleinschalige kinderopvangorganisaties heeft het Waarborgfonds \& Kenniscentrum Kinderopvang verzocht om in aanvulling op de netwerkkringen voor middelgrote en grote kinderopvangorganisaties een kennisgroep speciaal voor hen te organiseren. Op basis van deze verzoeken start het Waarborgfonds begin 2021 met een kennisgroep speciaal voor deze groep ondernemers. In de afgelopen jaren heeft het Waarborgfonds in het contact met ondernemers ervaren dat er grote behoefte is aan een netwerk van gelijkgestemde ondernemers, die zichzelf en hun organisatie willen professionaliseren en hierin willen leren met en van elkaar. Vanuit deze behoefte is de kennisgroep 'kleinschalige ondernemers' ontstaan.

Wil je meer weten over deze kringen? Neem dan contact op met het Waarborgfonds via info@netwerkprofessionalskinderopvang.nl.

\section{'Jonge kinderen dupe van crisis'}

Er is te weinig aandacht voor de gevolgen van de coronacrisis voor baby's en jonge kinderen. Dat blijkt uit onderzoek van het Verwey-Jonker Instituut. 'Meer gezinnen zijn kwetsbaar geworden door toegenomen stress, onzekerheid over werk en het wegvallen van bijvoorbeeld oppashulp van opa's en oma's,' aldus Onno de Zwart, directeur van het instituut, in het Nederlands Dagblad. 'Ook zijn niet alle hulpvoorzieningen goed toegankelijk gebleken.' De uitkomsten baren hem zorgen. 'De eerste duizend dagen van het leven van een kind zijn cruciaal voor zijn of haar toekomst. We weten dat jonge kinderen door zo'n crisis met levenslange effecten op hun fysieke en mentale gezondheid te maken kunnen krijgen.' Hoogleraar Tessa Roseboom, schrijver van het boek De eerste 1000 dagen, voegt hieraan toe dat eerdere perioden van crisis, zoals de hongerwinter en de Spaanse griep, meetbare schade opleverden bij jongere kinderen. En dat gevaar dreigt nu weer. 'Je hoeft op dit moment nog niet veel schade te zien, maar de effecten gaan over de heel lange termijn. Als er stress in het gezin is, bijvoorbeeld door baanverlies of geweld achter de voordeur als gevolg van de crisis, levert dat het jonge kind de meeste en langdurige schade op.' 'Je hoort verhalen over geweld achter de voordeur, bijvoorbeeld. We moeten nog meer inzetten op het creëren van sociale netwerken om de gezinnen heen, bijvoorbeeld via online gespreksgroepen.' De Zwart en Roseboom pleiten ervoor dat de rijksoverheid initiatief neemt om bij de jeugdgezondheidszorg en kinderopvang meer aandacht te vragen voor gezinnen met jonge kinderen.

\section{Naar belastingrechter voor vrijstelling btw}

Bij freelance pedagogisch medewerkers is onrust ontstaan omdat de Belastingdienst een einde wil maken aan de vrijstelling van btw voor zzp'ers. Daarom stapt bemiddelingsbureau Tadaah naar de rechter. 'We hebben zzp'ers momenteel heel hard nodig. Maar ze moeten natuurlijk wel weten waar ze aan toe zijn.' Zzp'ers in de kinderopvang hoefden tot nu toe geen btw af te dragen. Hierdoor is hun inzet voor kinderopvangorganisaties aanzienlijk goedkoper. 


\section{'Vooroordelen bestrijd je het beste op jonge leeftijd'}

Al vanaf jonge leeftijd maken kinderen onderscheid op grond van afkomst en hebben ze vooroordelen. Dit blijkt uit onderzoek van het Kennisplatform Integratie en Samenleving (KIS). Het aanpakken hiervan kan dus ook het beste op jonge leeftijd beginnen. Voor het onderzoek werden 200 wetenschappelijke studies doorgenomen en geanalyseerd. Het onderscheid komt omdat jonge kinderen het lastig vinden om elk kind als individu te zien. 'Ze maken onderscheid tussen mensen op grond van oppervlakkige kenmerken, waardoor verschillen tussen groepen mensen worden uitvergroot,' aldus het onderzoek. De voorkeur om met kinderen uit 'de eigen groep' te spelen, wordt al ge- zien op peuterleeftijd. Er lijkt zelfs een piek te zijn in vooroordelen bij kinderen in de kleuterleeftijd. Gedurende de basisschool kunnen deze vooroordelen weer iets afnemen of in ieder geval minder expliciet worden. De conclusie van de onderzoekers: het is aan te raden om al op kleuterleeftijd doordachte aanpakken in te zetten om vooroordelen, stereotyperingen en discriminatie te verminderen. Dat kan bijvoorbeeld door boekjes voor te lezen over vriendschappen tussen kinderen die een andere achtergrond hebben. Zo ontwikkelen kinderen positieve gevoelens naar kinderen met een andere achtergrond. Juist op jongere leeftijd, in de klas en bij de bso, is het belangrijk om hiermee aan de slag te gaan.

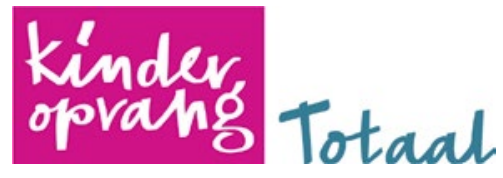

- ChristenUnie wil af van toeslagen

- Samenwerking aan de andere kant van de oceaan

- Campagne voor betere kinderopvang van start

- Nijpend tekort aan flexibele opvang

- Gesteggel tussen ouders en pm'ers over beslisboom

- Edwin Renzen over opstarten na onzekere tijd

LEES HET ACTUELE NIEUWS OP KINDEROPVANGTOTAAL.NL

\section{OPC's krijgen een wettelijke basis}

De uitzonderingspositie van ouderparticipatiecrèches (opc's), die worden gerund door ouders in plaats van beroepskrachten, wordt officieel vastgelegd in de wet. Dat meldt staatssecretaris Bas van 't Wout aan de Tweede Kamer. De opc's krijgen ontheffing van twee wettelijke kwaliteitseisen die voor de reguliere kinderdagverblijven wel gelden. Het gaat hierbij om de opleidingseis voor beroepskrachten en het vaste gezichtencriterium. De ouders die de opvang verzorgen, hoeven namelijk geen beroepskrachten te zijn die een opleiding hebben afgerond voor het werken in de kinderopvang. Doordat de opvang door ouders in dagdelen is ingedeeld, staan gedurende de dag verschillende ouders op de groep en is er dus geen vast gezicht op de groep. De opc's moeten wel aan alle andere eisen van de Wet kinderopvang voldoen. Momenteel zijn er in Nederland zeven opc's waar rond de 120 kinderen worden opvangen. Uit onderzoek van onder meer de VNG blijkt dat de kwaliteit van opc's voldoende is. 'Door formalisering van de opc's doet de

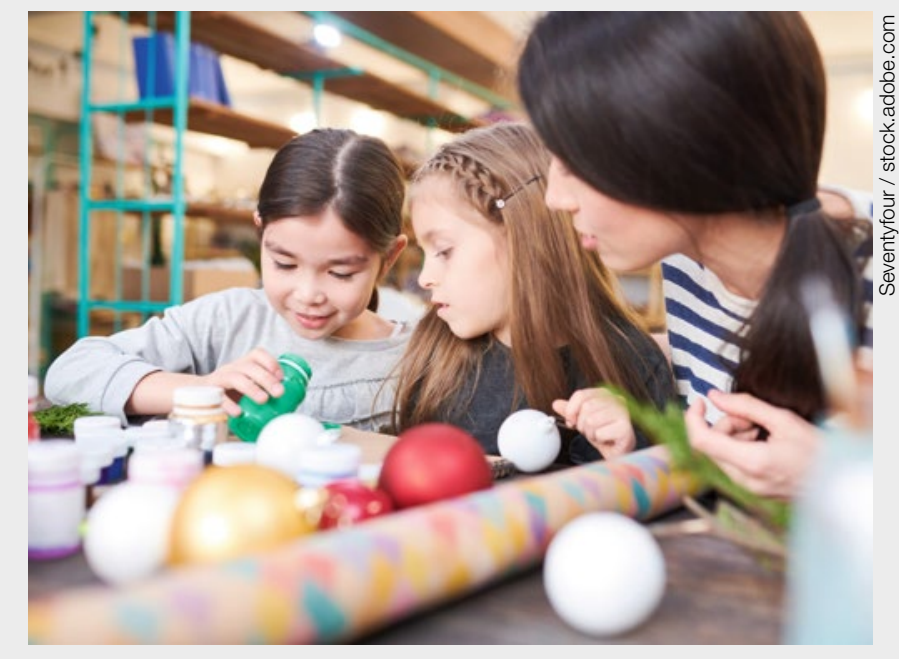

regering recht aan het jarenlange bestaan van opc's en de inzet en de rol van ouders bij het bieden van kinderopvang aan elkaars kinderen,' aldus de memorie van toelichting bij het bericht aan de Kamer. 


\section{Lezersreacties}

I Danielle van Oosterhout: 'Onze

organisatie heeft deze testen al en dat gaat zo supersnel. Heb je geen corona, kan je weer snel aan het werk.'

$\boldsymbol{f}$

Petra van Vuurde: 'Zo snel al? Misschien snapt minister Hugo de Jonge niet dat wij Nederland draaiende houden??? organisaties moeten deze zelf gaan bestellen, hoe wordt dit dan afgenomen en door wie?'

\section{$\mathbf{f}$}

Dionne Roukema- Luchtmeijer:

'Zou fijn zijn als wij als gastouders gebruik kunnen maken van deze sneltests via een $k d v$ in de buurt. Als de testen vanuit de overheid worden gefinancieerd, zou dat een goede optie zijn. Mocht een kdv de kosten zelf moeten betalen, is dat natuurlijk geen optie, maar lijkt me wel zo eerlijk als de overheid ze wel gratis aanbiedt, net als de GGD-testen van nu.' van de kinderopvang of stichting moet toch gewoon die testen zelf betalen? Waarom moet de overheid die van gastouders dan betalen?'

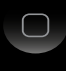

\section{'Eindelijk sneltesten op}

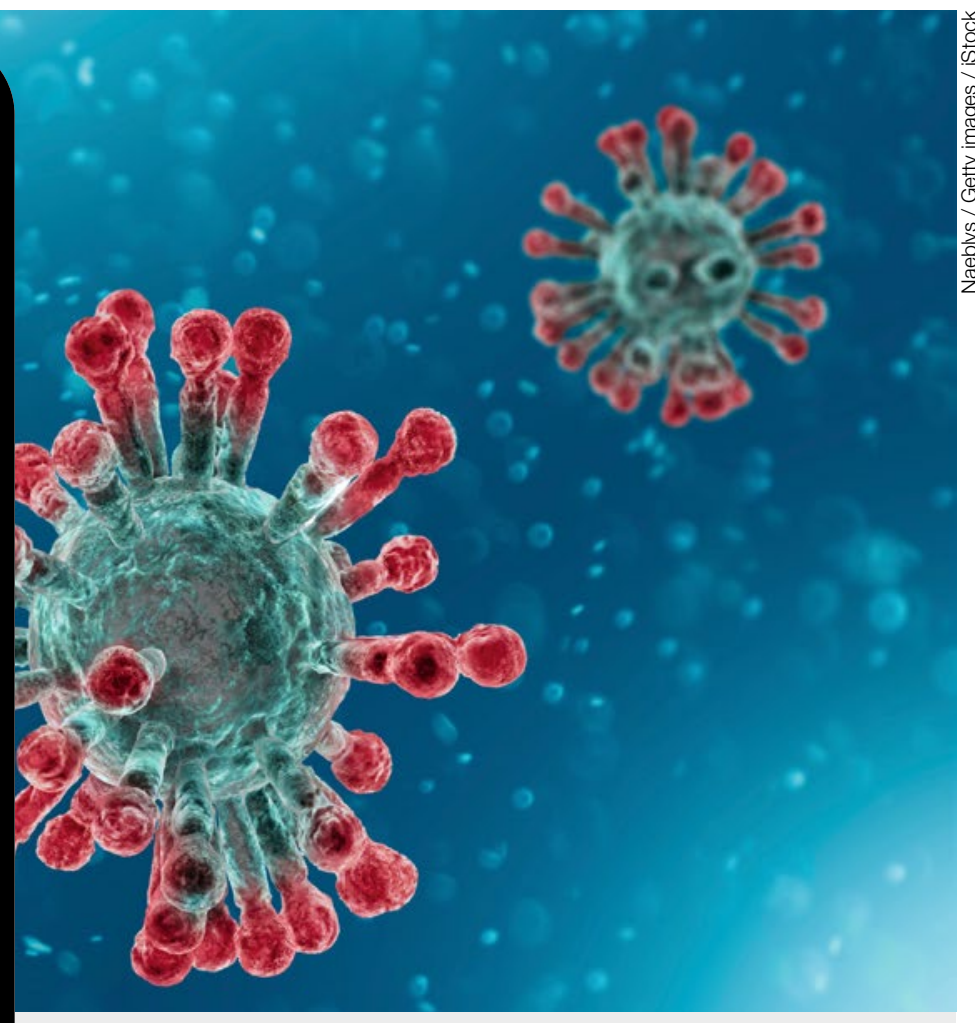

\section{Sneltest begin december beschikbaar}

Medewerkers van de kinderopvang met coronaklachten kunnen vanaf begin december een sneltest krijgen. Kinderopvangorganisaties moeten deze sneltests zelf bestellen. De sneltests zijn ook beschikbaar voor de zorg, het onderwijs en de politie. Medewerkers in de zorg krijgen voorrang, voor hen zijn de sneltests al eind november beschikbaar gekomen. Deze sneltests, die zijn goedgekeurd door het RIVM, zijn iets minder nauwkeurig dan de reguliere tests. Dit betekent dat je bij een positieve uitslag alsnog een reguliere test moet ondergaan. Het ministerie van VWS vindt dat de snelheid van de uitslag dat nadeel teniet doet. Naar verwachting leidt het sneltesten tot een vermindering van het ziekteverzuim, omdat medewerkers die zich hebben laten testen niet dagenlang thuis hoeven te wachten op de uitslag. De tekorten aan inzetbaar personeel in de kinderopvang zijn nog altijd hoog, bleek onlangs uit onderzoek van Kinderopvang werkt! In de dagopvang ervaart 45 procent van de organisaties een tekort aan pedagogisch medewerkers, in de buitenschoolse opvang is dat zelfs 52 procent. Sommige kinderopvangorganisaties testen hun medewerkers al op eigen initiatief bij commerciële aanbieders. Voor deze testen hebben het ministerie van VWS en het RIVM enkele uitgangspunten opgesteld. 


\section{Pleidooi voor toegankelijke opvang}

Ieder kind moet dezelfde kansen krijgen om zijn of haar talenten te ontwikkelen. De eerste jaren zijn daarvoor van cruciaal belang. Zeven landelijke organisaties pleiten daarom voor het recht op toegang tot kinderopvang van 16 uur per week, voor alle kinderen van nul tot vier jaar. De coronacrisis heeft nog eens laten zien dat de kinderopvang van vitaal belang is. Niet alleen voor de arbeidsmarkt en economie, maar ook voor de ontwikkeling van jonge kinderen, aldus de zeven organisaties. Het gaat om de brancheorganisaties BOinK, BK en BMK, en om VNG, SWN, PO-Raad en Regiegroep Kindcentra 2020.

De kinderopvang in Nederland is echter niet voor iedereen bereikbaar en betaalbaar, vervolgt het pleidooi. Het kinderopvangstelsel is versnipperd en onnodig ingewikkeld. Het systeem werkt kansenongelijkheid en segregatie in de hand, al vóór het vierde levensjaar van het kind. Dat moet anders.'De tijd is rijp voor inclusieve kindvoorzieningen zodat alle kinderen dezelfde kansen krijgen en met zo weinig mogelijk achterstanden aan de basisschool beginnen. Voor kinderen die met een achterstand aan de basisschool beginnen, is het lastig deze nog in te halen.'

Opvallend is dat de organisaties niet oproepen tot gratis kinderopvang, zoals enkele politieke partijen willen. De organisaties pleiten wel voor een eenduidig stelsel voor alle kinderen van 0 tot 4 jaar met één wettelijk en financieel kader. Dit moet leiden tot laagdrempelige toegang tot voorzieningen. De complexiteit en de kosten van het huidige stelsel werpen drempels op voor ouders. Zoals het feit dat hun recht op kinderopvangtoeslag verandert zodra hun werksituatie verandert. Dit brengt onzekerheid mee voor een groep ouders zonder vaste baan. Voor gemeenten en voor onder-

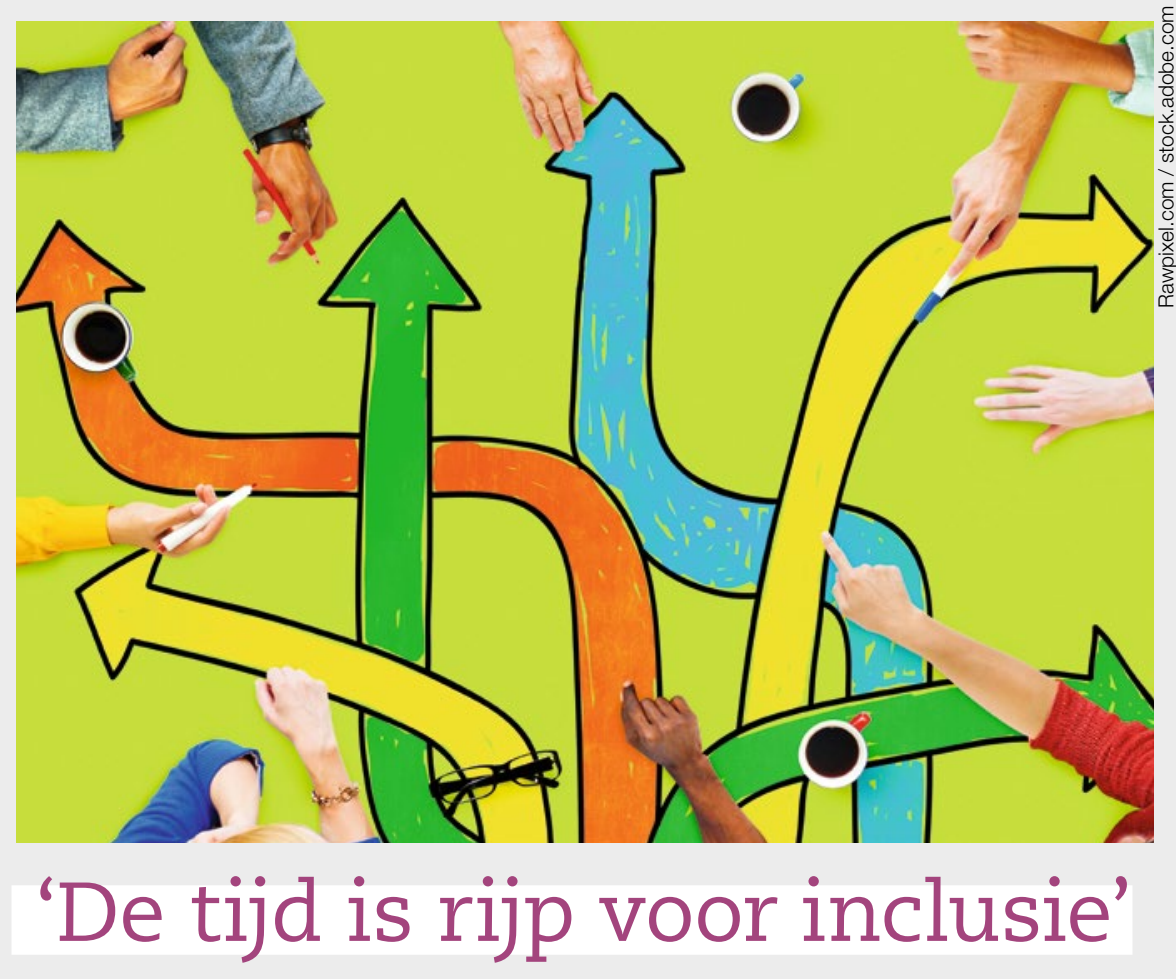

nemers leidt het stelsel tot administratieve lasten. Daar zijn hoge uitvoeringskosten mee gemoeid.

De organisaties stellen hier onder meer de volgende veranderingen tegenover: eén wettelijk en financieel kader; investeringsmiddelen voor kwaliteit en opleidingen; voor alle ouders dezelfde financiële voorwaarden (de ouderbijdrage mag geen belemmering zijn voor deelname); de mogelijkheid voor gemeenten om financiële drempels voor ouders te beslechten en een voldoende aanbod te garanderen.

\section{2 diploma's terug op lijst}

Twaalf diplomass die waren vervallen voor de dagopvang zijn terug op de diplomalijst, maar alleen in combinatie met aanvullend bewijs. Dat hebben cao-partijen besloten. Zonder geldig aanvullend certificaat kan men met deze diploma's instromen als pedagogisch medewerker in ontwikkeling, terwijl er wordt gewerkt aan het behalen van een aanvullend certificaat. In totaal gaat het om de volgende twaalf diploma's: Mbo niveau 4 (voorgangers SPW-4), Activiteitenbegeleider (AB), Activiteitenbegeleiding (AB), Agogisch Werk, Inrichtingswerk (IW), Residentieel werk (RW), Sociaal-agogisch II (MBO-SA-II richting (semi)residentiele hulpverlening, Hbo bachelor niveau (voorgangers SPH), Activiteitenbegeleiding (AB), Aktiviteitenleidersopleiding (van Mikojel: Middeloo, Kopse Hof, Jelburg of Sittard), Educatieve therapie (van Mikojel), Inrichtingswerk (IW), Jeugdwelzijnswerk en Kreatief educatief Werk. Zonder aanvullend bewijs blijven deze diploma's onveranderd voor de buitenschoolse opvang kwalificeren. Bekijk het overzicht van de actuele lijst met certificaten op www.kinderopvangwerkt.nl. 